\title{
A IMPORTÂNCIA DA TEORIA DO DISCURSO EM ERNESTO LACLAU COMO ABORDAGEM TEÓRICA PARA A ANÁLISE DE POLÍTICAS CURRICULARES PARA A EDUCAÇÃO DO CAMPO
}

\author{
Apresentação: Comunicação Oral \\ Jéssica Rochelly da Silva $\operatorname{Ramos}^{1}$; Katia Silva Cunha ${ }^{2}$
}

\begin{abstract}
Resumo
O presente artigo apresenta um ensaio crítico sobre a importância da Teoria do Discurso para análise de políticas para a Educação do Campo a partir da corrente teórica pós-estruturalista. Esta pesquisa de cunho bibliográfico, nasce a partir do Estado do Conhecimento realizado na ANPEd, ao constatarmos que as análises em Políticas Educacionais para a Educação do Campo, em seu contexto micro e macro, são escassas nestes espaços de propagação de pesquisas ocupando o lugar das ausências. No entanto, apresentamos ao longo do texto o pós-estruturalismo como uma teoria analítica para as Políticas Públicas de Educação do Campo, esta teoria que não se constitui como um movimento ou como um conjunto de fundamentos epistemológicos que buscam identificar estruturas universais. Para tanto, realizamos uma pesquisa documental e bibliográfica, nos baseando principalmente nos estudos de Rodrigues e Mendonça (2008), Lopes (2013), Cunha (2013), entre outros autores, destacando que as políticas para a educação do Campo são consideradas neste texto enquanto discurso, o que nos direciona e nos propõe fazer uma reflexão sobre a linguagem, o sujeito e a história. Por fim, situamos o pós-estruturalismo na perspectiva de Laclau (1993) e abordamos sua crítica ao marxismo para compreendermos a importância de analisar políticas no contexto microssocial e macrossocial a partir da Teoria do Discurso, apontando o pós-estruturalismo como uma teoria que possibilita uma análise mais refinada e pertinente dos múltiplos antagonismos sociais possíveis considerando a infinidade de identidades existentes no social.
\end{abstract}

Palavras-chave: Políticas Públicas, Educação do Campo, Estado do Conhecimento, Pósestruturalismo, Teoria do Discurso.

\section{Introdução}

O objetivo deste texto é apresentar algumas considerações teórico-metodológicas sobre a análise das políticas educacionais a partir de um olhar pós-estruturalista. Este texto

\footnotetext{
${ }^{1}$ Pedagoga pela Universidade Federal de Pernambuco (UFPE) no Centro Acadêmico do Agreste (CAA) e mestranda pelo Programa de Pós-Graduação em Educação Contemporânea- PPGEDUC/ UFPE/ CAA, Caruaru, Pernambuco, Brasil, e-mail: rochellyramos@ hotmail.com.

${ }^{2}$ Professora Adjunta da Universidade Federal de Pernambuco (UFPE), no Centro Acadêmico do Agreste (CAA). Docente do Programa de Pós-Graduação em Educação Contemporânea (PPGEDUC), do Programa de PósGraduação em Educação, Ensino de Ciências e Matemática (PPGECM) e do Núcleo de Formação Docente, no Centro Acadêmico do Agreste, Pedagoga pela UFPE/CAA, Mestrado e Doutorado em Educação Superior pela UFPE. e-mail: kscunha@gmail.com.
} 
nasce a partir do Estado do Conhecimento realizado no GT03- Movimentos Sociais e no GT05- Estado e Política Educacional, nas modalidades Comunicação Oral (CO) e Apresentação em Pôster (AP), publicados nas Reuniões Anuais da Associação Nacional de Pesquisas em Educação (ANPEd) no período de 2002 a 2015, simultaneamente aos estudos teóricos realizados a partir da disciplina Políticas de Educação no Brasil no Programa de PósGraduação em Educação Contemporânea (PPGEDUC), pela Universidade Federal de Pernambuco- UFPE, no Centro Acadêmico do Agreste- CAA.

Sobre a disseminação de estudos e publicações que contemplem o estudo e a análise de políticas educacionais na ANPEd, podemos inferir que os estudos voltados ao tratamento de Políticas Públicas para a Educação do Campo, pautados em abordagens teóricas que ampliem e abordem para além da ideia de classes econômicas, são escassas nesses ambientes de propagação da pesquisa, e concomitante a isto, identificamos a necessidade de discutir a importância da análise de políticas públicas para a Educação do Campo no âmbito educacional, tanto na sua construção quanto na sua implementação, bem como as abordagens teórico-metodológicas que compreendam o estudo dessas políticas no âmbito macro e micro.

Ao constatar as ausências nos estudos e análises sobre políticas nestes ambientes de propagação de pesquisa buscamos com este artigo, apresentar uma discussão acerca da importância de analisar as políticas públicas para a Educação do Campo a partir da corrente teórica pós-estruturalista tendo como base a concepção epistemológica de Ernesto Laclau, pois acreditamos na relevância de analisar as políticas de forma minuciosa e abrangente, compreendendo as diferenças de identidades e os contextos em que os discursos são construídos. Sendo assim, este estudo de cunho bibliográfico, destaca a relevância da Teoria do Discurso para a discussão de políticas educacionais, visto que as pesquisas sobre políticas públicas educacionais nos seus contextos micro e macro são escassas, ocupando assim o lugar das ausências.

\section{FUNDAMENTAÇÃO TEÓRICA:}

\subsection{O Pós-estruturalismo na análise de Políticas Públicas para a Educação do Campo: Implicações a partir das produções na ANPEd.}

As políticas públicas educacionais, principalmente voltadas à Educação do Campo, no Brasil, tem sido pouco presente nas discussões teóricas e nas abordagens que compõem a literatura nacional sobre a análise de políticas. Destacamos ainda, que por ser uma discussão, 
ainda em construção, cresce o índice de presença e de tratamento a passos lentos nos periódicos, revistas eventos científicos e bancos de teses e dissertações, e por isso nos propomos a analisar dois Grupos de Trabalhos (GTs), visto que, ainda não temos um GT específico para a Educação do Campo.

Para sistematizar as informações, facilitar as análises das pesquisas publicadas nas Reuniões Anuais Nacionais da ANPEd (2002 a 20015) e registrar efetivamente o quantitativo de trabalhos que trate do objeto em análise, optamos por desenvolver a forma de organização a seguir:

QUADRO 1. PESQUISAS EM FORMATO DE COMUNICAÇÕES ORAIS E PÔSTERES DA ANPED ENTRE OS ANOS DE 2002 A 2015 NOS GTS DE MOVIMENTOS SOCIAIS E ESTADO E POLÍTICA EDUCACIONAL

\begin{tabular}{|c|c|c|c|c|c|c|c|c|c|c|}
\hline \multirow[t]{3}{*}{ ANO } & \multicolumn{4}{|c|}{$\begin{array}{l}\text { QUANTITATIVO GERAL DE TRABALHOS } \\
\text { APRESENTADOS NOS GTS }\end{array}$} & \multirow[t]{4}{*}{$\begin{array}{l}\text { TOTAL } \\
\text { POR ANO }\end{array}$} & \multicolumn{4}{|c|}{$\begin{array}{c}\text { TRABALHOS IDENTIFICADOS } \\
\text { COM O OBJETO "EDUCAÇÃO DO } \\
\text { CAMPO" }\end{array}$} & \multirow[t]{4}{*}{$\begin{array}{l}\text { TOTAL } \\
\text { POR } \\
\text { ANO }\end{array}$} \\
\hline & \multicolumn{2}{|c|}{$\begin{array}{l}\text { GT03- } \\
\text { MOVIMENTOS } \\
\text { SOCIAIS }\end{array}$} & \multicolumn{2}{|c|}{$\begin{array}{l}\text { GT05- ESTADO E } \\
\text { POLÍTICA } \\
\text { EDUCACIONAL }\end{array}$} & & & & & & \\
\hline & $\mathrm{CO}$ & AP & $\mathrm{CO}$ & $\mathbf{A P}$ & & \multicolumn{2}{|c|}{ GT03 } & \multicolumn{2}{|c|}{ GT05 } & \\
\hline & & & & & & CO & AP & CO & AP & \\
\hline 2002 & - & - & - & - & 00 & - & - & - & - & 00 \\
\hline 2003 & - & - & - & - & 00 & - & - & - & - & 00 \\
\hline 2004 & - & - & - & - & 00 & - & - & - & - & 00 \\
\hline 2005 & 19 & 07 & 15 & 04 & 45 & 01 & - & - & - & 01 \\
\hline 2006 & 11 & 01 & 17 & 04 & 33 & 01 & - & - & - & 01 \\
\hline 2007 & 09 & 01 & 24 & - & 34 & - & - & - & - & 00 \\
\hline 2008 & 12 & 03 & 18 & 04 & 37 & 02 & 01 & - & - & 03 \\
\hline 2009 & 07 & 02 & 12 & 01 & 22 & 01 & 02 & 01 & - & 04 \\
\hline 2010 & 12 & 03 & 20 & 04 & 39 & 02 & 01 & - & - & 03 \\
\hline 2011 & 16 & 03 & 22 & 03 & 44 & 05 & 02 & - & - & 07 \\
\hline 2012 & 15 & 05 & 19 & 02 & 41 & 03 & 02 & 02 & - & 07 \\
\hline 2013 & 08 & 05 & 17 & 04 & 34 & 02 & 01 & - & - & 03 \\
\hline 2015 & 21 & 03 & 30 & 11 & 65 & 04 & 01 & - & - & 05 \\
\hline $\begin{array}{l}\text { TOTAL } \\
\text { GERAL }\end{array}$ & 130 & 33 & 194 & 37 & 394 & 21 & 10 & 03 & - & 34 \\
\hline
\end{tabular}

Fonte: www.anped.org.br

Neste quadro podemos ver, sistematicamente, os números anuais e gerais de pesquisas/trabalhos apresentadas em $\mathrm{CO}$ ou em AP publicadas nas Reuniões Científicas Anuais da ANPEd no período de 2002 a 2015, bem como os números de pesquisas/trabalhos que estão vinculadas à Educação do Campo. Gostaríamos de situar o número geral de 394 publicações nos GT03 e no GT05 no respectivo período, porém 34 publicações tratariam especificamente da Educação do Campo, aproximadamente 8,5\% dos trabalhos voltados ao objeto em análise. Apresentados os dados coletados na ANPEd citados acima, podemos inferir que há uma ausência de pesquisas no âmbito das Políticas Públicas para a Educação do Campo, nosso objeto de estudo e de pesquisa neste trabalho, pois, entre 34 trabalhos inscritos, apenas 3 se encontram direcionados para a análise de Políticas, cerca de 1,02\% dos trabalhos 
que abordam a Educação do Campo se voltam para as políticas. Esta ausência de pesquisas científicas na área, compreende uma de nossas justificativas, especificamente a relevância social e acadêmica de ampliar os estudos acerca das análises das Políticas Públicas para a Educação do Campo, em seus contextos micro e macro, de modo a entender os contextos discursivos que permeiam tais políticas, compreendendo nas políticas para a Educação do Campo os sentidos e significados que produzem, bem como suas implicações no âmbito da política enquanto prática no e do social.

A partir desta pesquisa na ANPEd, denominada como Estado do Conhecimento, destacamos que as abordagens teóricas-metodológicas utilizadas nas análises das políticas educacionais são vastas, algumas dessas, na medida em que trabalham na dimensão macrossocial acabam unificando as diferenças, as lutas e anseios dos diferentes grupos sociais. Dessa forma, acreditamos na necessidade de discutir Políticas Públicas para a Educação do Campo a partir de uma abordagem que contemple as especificidades dos sujeitos, suas lutas e seus interesses, entendendo que tais sujeitos apesar de estarem reunidos em consensos locais e parciais na busca de reconhecimento do Estado.

O pós-estruturalismo não se constitui como um movimento ou como um conjunto de fundamentos epistemológicos que busca identificar estruturas universais comum à mente humana e a todas as culturas. Esta corrente faz uma crítica ao cientificismo das ciências humanas, tendo por base os elementos da linguística supracitados.

De acordo com Lopes (2013), as possíveis estruturações passam a serem compreendidas como desestruturadas e descentradas, e assim, nos faz necessário compreender que,

Há uma busca por salientar a pluralidade dos jogos de linguagem que tornam provisório o processo de significação, sem fechamento final, terreno de diferença sempre passíveis de produzirem novos sentidos (TORFING, 1999 apud LOPES, 2013, p. 13).

A autora ainda ressalta, que nesse contexto "a ideia de estrutura é substituída pela ideia de discurso: não há estruturas fixas que fechem de forma definitiva e significação, mas apenas estruturações e reestruturações discursivas" (idem, 2013). Em relação aos questionamentos à estrutura, pela crítica a fixação de caráter definitivo e que anula as significações, destaca-se nessa corrente teórica a contingência e são questionadas noções como a transcendência e a universalidade.

De fato, esses sujeitos por serem históricos e de realidades plurais, tornam-se impossíveis de serem contemplados por abordagens teóricas-metodológicas que universalizem grupos e se interessem por apenas uma esfera da dinâmica de sua construção 
social e histórica, sendo inviável entender os movimentos das transformações sociais e da construção do indivíduo realizando uma pesquisa direcionada as questões iniciais e gerais da política, o macro.

Concordamos com Jobert e Muller (1987) apud Azevedo (2004, p. 59-60) quanto à concepção de política. Sendo assim, quando nos referimos a política educacional estamos atribuindo este termo a um programa de ação onde a sociedade estabelece sobre si um modelo educativo e tenta o colocar em ação.

Sendo a política educacional parte de uma totalidade maior, deve-se pensa-la sempre em sua articulação com o planejamento mais global que a sociedade constrói como o seu projeto e que se realiza por meio da ação do Estado. São, pois, as políticas públicas que dão visibilidade e materialidade ao Estado e por isto, são definidas como sendo " o Estado em ação" (AZEVEDO, p.59-60, 2004).

Portanto, salientamos a necessidade de analisar as políticas públicas como um programa em ação, não nos esquecendo que a escola e a sala de aula são espaços onde as definições de política e o planejamento da sociedade são materializados.

Compreender a política como ação do Estado e como uma ação que não parte do zero, nos imprime a pensar a política como

O conjunto de práticas, instituições e discursos os quais buscam estabelecer uma ordem e recriam as regras através das quais seja possível a convivência humana, um contexto onde a conflitividade é presente, tendo em vista a dimensão antagônica do político, inerente e constitutiva das relações humanas (LACLAU; MOUFFE, 2006 apud CUNHA, 2013).

Neste sentido, percebemos a necessidade de entender as políticas como conjunto de ações constituídas por discursos, bem como compreendemos a importância de fazer uma análise, que nos permita ir além de palavras e que contemplem os diferentes contextos, sujeitos e sentidos das práticas sociais.

Assim sendo, o tratamento das políticas educacionais numa abordagem pósestruturalista, não se reduz a considerar a linguagem como única forma de entendimento e interpretação, pois, a linguagem não deve ser vista "como o centro da análise, mas como uma das dimensões das práticas sociais, o que implica a inclusão dos sujeitos e sua relação com um social, que é constituído e transformado" como afirma Cunha (2013, p. 262).

Em consonância com Azevedo (2004) no que concerne à concepção de política e o papel do Estado, Celina Souza (2006) ainda compartilha a ideia de política como ações pensadas para impulsionar a mudança no mundo real, e admite que,

Pode-se então, resumir política pública como campo do conhecimento que busca, ao mesmo tempo, "colocar o governo em ação" e/ou analisar essa 
ação (variável independente) e, quando necessário, propor mudanças no rumo ou curso dessas ações (variável dependente) (SOUZA, 2006, p.26).

Portanto, precisamos entender, sobretudo, que analisar políticas públicas significa muitas vezes estudar o governo em ação, sendo assim, um processo complexo, que abarca desde o desenho, formulação, os desdobramentos em planos, bases de dados, sistemas de informação, até a sua implementação, ficando submetidas a sistemas de avaliação e acompanhamento (Souza, 2006, p. 26).

Diante disso, percebemos a importância de aguçar nossos olhares e interpretação para além do quadro mais amplo onde as políticas são elaboradas, cabendo-nos investir num estudo mais profundo onde o cotidiano escolar seja também visto e analisado, este que de acordo com Azevedo (2008, p. 59) representa o elo final da concretude da política.

Para tanto, gostaríamos de situar que utilizamos a teoria pós-estruturalista no tratamento e na análise das políticas públicas. De acordo com Michael Peters (2000) o termo pós-estruturalismo não minimiza as diferenças dos sujeitos e nem tampouco traz a ideia de estrutura e unidade. $\mathrm{O}$ autor enfatiza a caracterização do termo ao afirmar que

O pós-estruturalismo pode ser caracterizado como um modo de pensamento, um estilo de filosofar e uma forma de escrita, embora o termo não deva ser utilizado para dar qualquer ideia de homogeneidade, singularidade ou unidade. O termo "pós-estruturalista" é, ele próprio, questionável (PETERS, 2000, p. 28).

A escolha do pós-estruturalismo como teoria fundante para embasar os nossos escritos se dá por acreditarmos que os sujeitos são formados a partir de processos socioculturais, processos estes, construídos a partir das múltiplas experiências vivenciadas nos mais variados contextos, vivências que ao longo desses movimentos possibilita o desenvolvimento e construção de identidades que os definem como sujeitos.

Portanto, o pós-estruturalismo é, sobretudo, uma forma de dialogar com as unidades/singularidades dos sujeitos, pois possibilita a compreensão dos contextos múltiplos que permeiam o social, sendo a Teoria do Discurso, o viés teórico-metodológico que rompe com as abordagens que discutem e analisam as políticas de forma ampla, que considera e se volta apenas às questões de classes.

\subsection{A Teoria do Discurso como abordagem teórico-metodológica para a análise de políticas em Educação do Campo}


A nossa pesquisa intenta para explicações parciais e localizadas sobre os processos de construção das políticas públicas para a educação do campo, vislumbrando a possibilidade de analisar as políticas em sua completude, desde o seu funcionamento que é contingente e instável num campo de disputas e conflitos que ao ser analisada a partir da categoria discurso até as suas implicações no âmbito da prática. Dessa forma, através da Teoria do Discurso como base epistemetodológica para a análise de políticas podemos, de fato, compreender a prática relacional em suas contradições, ideologias e mediações que ocorrem na realidade a ser estudada.

Pensar em políticas públicas na perspectiva de Laclau e Mouffe, é pensar esta categoria considerando o não fechamento do social e, portanto, um campo (do social) não estático e indefinido. Pensar nas políticas públicas de educação do campo é pensar que estas políticas são constituídas por sujeitos, descentrados, que não tem domínio do seu consciente nem sobre os sentidos do que suas falas produzem, é compreender a linguagem como constituinte do social e entender que estamos simbolicamente mediados no social e, portanto, esta linguagem nos permite entender o que de fato é políticas públicas, educação do campo e seus sentidos, estes, construídos a partir de discursos (práticas que constituem o social) produzidos principalmente por atos de poder e que lutam por hegemonia. Neste sentido, a TD surge como uma abordagem teórica capaz de romper com os paradigmas científicos na sociedade, considerando sobretudo, as diferenças dos sujeitos e ampliando os estudos e análises, para além dos aspectos socioeconômicos/ de classes.

Segundo Laclau (1993), este autor que teve como ponto de partida uma posição crítica à teoria marxista, o qual considerava o marxismo como sendo uma concepção essencialista de sociedade, ancorada numa lógica reducionista do sujeito e das relações sociais, reduzindo a compreensão ao antagonismo do capital versus trabalho.

Concomitante a isto, Mendonça e Rodrigues (2008) ao retratar a crítica de Laclau ao marxismo, enfatiza que esse projeto teórico é incapaz de dar conta da compreensão das relações sociais contemporâneas.

Em oposição [ao Marxismo], Laclau argumenta que o que existe efetivamente é um complexo espectro social formado por uma infinidade de identidades, constituídas a partir das relações discursivas antagônicas distintas do antagonismo de lasse que, segundo sua análise, têm locus particular e não um a priori universal neste intricado jogo. Essa complexidade do social não é percebida e/ou alcançada pelo marxismo, o que retira desta corrente teórica a capacidade de análise mais refinada e pertinente dos múltiplos antagonismos sociais possíveis MENDONÇA E RODRIGUES, 2008, p. 26). 
De fato, concordamos com as concepções de Laclau em relação as várias dimensões, as múltiplas facetas e os diversos discursos existentes na sociedade, bem como, na interpretação de que uma corrente teórica capaz de reduzir uma análise de extensão densa a apenas um antagonismo de classe é precário no tratamento de políticas públicas.

Nesta perspectiva, reconhecemos que o pós-estruturalismo se faz de extrema importância na análise das políticas educacionais, por ser, para além de uma teoria, um movimento onde complexas formas de pensamento materializam-se em práticas sociais.

Michael Peters (2000) sobre a interdisciplinaridade e abrangência dessa corrente teórica, discorre sobre as diferentes correntes que o pós-estruturalismo incorpora em suas críticas e, concomitante a isto, evidencia que esta teoria de caráter inovador voltada para uma desconstrução na análise literária

Não pode ser reduzido a um conjunto de pressupostos compartilhados, a um método, a uma teoria ou até mesmo a uma escola. É melhor referir-se a ele [O pós-estruturalismo] como um movimento de pensamento - uma complexa rede de pensamento - que corporifica diferentes formas de prática crítica. $\mathrm{O}$ pós-estruturalismo é, decididamente, interdisciplinar, apresentando-se por meio de muitas e diferentes correntes (PETERS, 2000, p. 29).

A pesquisa, nesse contexto, está alicerçada em uma perspectiva crítica, sinalizando como principal objetivo uma análise política aprofundada e atenta a várias dimensões e estabelecendo vínculos com contextos diferenciados, como o econômico, o social e o político.

A teoria pós-estruturalista empreendida por Ernesto Laclau e Mouffe, tem o potencial de ser uma ferramenta de compreensão do social e, sendo assim, faz intersecções de noções centrais para discutir as relações sociais. Ao tratar da teoria pós-estruturalista e suas categorias centrais a partir de uma análise em Laclau e Mouffe, Mendonça e Rodrigues (2008) ressalta que,

Uma vez que o seu próprio entendimento dá-se aqui a partir da construção de ordens discursivas, sendo a questão do poder central e constituidora de relações sociais. Tendo como ponto de partida a centralidade das categorias de poder e de discurso - que após se desdobrarão em outras noções centrais à teoria, como pontos nodais, articulação, hegemonia, significantes vazios, populismo (MENDONÇA E RODRIGUES, p. 25-26, 2008).

Ernesto Laclau (2015) vem a articular uma série de conhecimento e conceitos de diversas áreas do conhecimento, inclusive do marxismo, o estruturalismo e o pósestruturalismo. A partir das noções advindas desses diferentes campos de conhecimento, o autor constrói um aparato teórico bastante original, contemporâneo e pós-estruturalista. Essa matriz teórica pós-estruturalista na concepção de Mendonça e Rodrigues (2008, p. 26) vem a 
“contemplar a contingência, a precariedade, a indeterminação e o paradoxo como dimensões ontológicas do social”.

Uma categoria bastante abordada e contemplada nos inscritos de Laclau e Mouffe (1987) é o rompimento com o dualismo estrutura/ação, desse modo, há uma ausência de estruturalidade na própria estrutura. Sendo assim, o fato dos teóricos acreditarem na existência de uma estrutura, não condiz com uma determinação em relação a ação do sujeito.

Outro conceito fundante das suas obras é a questão da universalidade e ao mesmo tempo do universal, pois estas categorias geram um limite para sistematizações e generalizações, como podemos observar Burity (2008) ao discutir sobre a teoria da hegemonia de Ernesto Laclau e a relação com o discurso, a política e o sujeito faz uma ressalva enfatizando que,

\begin{abstract}
A teoria que é possível elaborar sobre a política sempre estará marcada pela contingência, pela historicidade, pelas múltiplas formas através das quais tudo o que é poderia ser (ter sido) diferente, e sê-lo num dado momento, sob dadas condições de possibilidade. Mais, tudo o que é (foi) está (estava) habitado por uma dimensão de indeterminação e de falta constitutiva, de modo que não está dado numa identidade, num sujeito ou numa posição estrutural o dever- ser e o poder- ser do existente (BURITY, 2008, p. 36).
\end{abstract}

Portanto, compreendemos que os estudos em política, principalmente no âmbito educacional, não partem de um contexto isolado, tampouco são fatos que acontecem a partir de um olhar penetrante de um estado e/ou governo que prioriza uma sociedade em suas lutas.

$\mathrm{Na}$ concepção do espaço social enquanto espaço discursivo, Laclau demonstra uma preocupação com o conceito da totalidade tratado por alguns teóricos da corrente marxista. Para ele, esta totalidade engloba tanto os elementos linguísticos, quanto os elementos extralinguísticos, essa totalidade que é conceituada como discurso.

Para Laclau (1993, p. 115) podemos categorizar discurso como um "conjunto sistemático de relacões". Dessa forma, toda configuração social, neste contexto, é uma configuração significativa onde o agente social constrói o discurso e a palavra é inteiramente dependente de um contexto.

Ao criticar o marxismo por generalizar as diferenças existentes entre os grupos sociais categorizando e reduzindo apenas para a relação de classes, Laclau (1993) nos alerta sobre a necessidade de compreender que os discursos igualitários e de diereitos tem um papel fundamental na reconstrução de novos imaginários coletivos, assim como, no reconhecimento de identidades invisíveis socialmente.

Em estas condiciones, la radical inestabilidad y amenaza a las identidades sociales generadas por la expansión capitalista conduce a nuevas formas de imaginário colectivo que reconstuyen de um modo fundamentalmente nuevo 
essas identidades amenazadas. Nuestra tesis es que los discursos igualitários y los discursos sobre los derechos juegan um papel fundamental em la reconstrucción de las identidades coletivas (LACLAU, 1993, p. 143).

Assim, podemos enfatizar a importância de entender os fatores que influência as elaborações das políticas públicas por uma teoria que estabeleça um comprometimento com o conhecimento acerca das constituições e o desenvolvimento da sociedade, bem como as representações sociais as quais as políticas públicas buscam atender através de suas ações.

\section{Caminhos Teórico-Metodológicos da Pesquisa}

Esta pesquisa surge da inquietação a partir dos resultados obtidos com o Estado do Conhecimento na ANPEd, onde suscitou-se que a grande maioria das pesquisas sobre Políticas Públicas para a educação do campo tem suas análises respaldadas nas questões socioeconômicas, concomitante com os estudos bibliográficos realizados no Componente Curricular 'Políticas em Educação no Brasil' do Programa de Pós-Graduação em Educação Contemporânea - PPGEDUC, pela Universidade Federal de Pernambuco- UFPE, no Centro Acadêmico do Agreste- CAA.

Este estudo pautou-se em uma abordagem qualitativa, uma vez que quando tratamos de analisar aspectos voltados a educação não podemos apenas quantificar, entretanto, a pesquisa não nega a importância do aspecto quantitativo, visto que foi utilizado em determinados momentos quando e sempre que necessário para registro das informações no quadro explicativo. A pesquisa qualitativa considera que há uma relação dinâmica entre o mundo real e o sujeito e que essa subjetividade nessa relação não pode ser quantificada (MINAYO, 2012), quanto ao tipo de abordagem, justificamos nossa escolha na medida em que necessitamos compreender os discursos que estão sendo produzidos acerca da educação do campo, sendo que estes não podem ser quantificáveis.

A busca bibliográfica foi realizada desde o mês de agosto de 2015 a fevereiro de 2016, na ANPEd abrangendo estudos/artigos publicados entre o período de 2002 a 2015, quanto ao período de curso na disciplina, ocorreu no segundo semestre de 2015. Os descritores/palavraschave utilizados/as como base para as pesquisas foram: Políticas Públicas, Teorias, Teoria do Discurso, Políticas e Educação do Campo. Realizou-se um levantamento das produções científicas na ANPEd e após a leitura dos resumos que dialogavam com o nosso objeto de estudo, organizamos as informações explícitas em um quadro explicativo, o qual nos proporcionou junto aos estudos realizados no âmbito das Políticas Públicas, Educação do 
Campo e Teoria do Discurso, a conclusão de que há ausências da análise de Políticas Públicas para a Educação do Campo a partir de uma teoria que transcenda o dualismo capital $\mathrm{x}$ trabalho, nas bases de dados de propagação de pesquisa, especificamente na ANPEd.

Assim sendo, inferimos que nossa pesquisa se inscreve no campo teórico da Teoria do Discurso (TD) de Ernesto Laclau e Chantal Mouffe, uma abordagem teórica e analítica que nos possibilita compreender o social a partir da perspectiva discursiva. Tendo por base a compreensão de política enquanto discurso, é que construímos este estudo, tecendo considerações acerca da importância do estudo e das análises das Políticas Públicas para a Educação do Campo, especificamente, as contribuições da Teoria do Discurso como abordagem teórica e metodológica que considera as diferenças, os contextos discursivos em que se constroem estes discursos e, portanto, uma abordagem que melhor compreende a política em sua completude.

\section{Considerações Parciais}

A partir dessa pesquisa, e principalmente com as leituras realizadas durante os trabalhos desenvolvidos no âmbito do campo das políticas em estudo podemos, por fim, refletir e inferir os resultados alcançados dissertando acerca da importância de analisar as políticas educacionais a partir de uma corrente teórica que não amenize as diferenças dos grupos sociais, numa totalidade que universalize as identidades.

Retomando a pergunta inicial que orientou o interesse na escrita deste artigo: Qual a importância de analisar as políticas educacionais para a Educação do Campo a partir da corrente teórica pós-estruturalista, com base nos estudos de Ernesto Laclau? As nossas conclusões apontam que há diversas formas de fazer ciências, tanto como não há um único paradigma que possa responder a todas as questões passíveis de serem analisadas em pesquisas na área de políticas educacionais.

Mesmo assim, precisamos nos atentar e repensar as formas de análise de políticas na contemporaneidade, pois devemos compreender que a as políticas não podem ser tomadas como claras e fixas e desconsiderar a permanente luta de sentidos que está em jogo (BALL e MAINARDES, 2011).

Enfim, dado o exposto podemos afirmar que toda luta e conquista no âmbito de uma política é uma ação coletiva, de interesses, de diferentes grupos, bem definidos e unidos numa

constante ação e luta. É desse embate, entendido como uma ação social incessante, que nascem as formulações de políticas voltadas aos interesses de grupos sociais de necessidades 
distintas, porém, muito mais além dos planos a política precisa ser colocada em ação, essa é a materialização da política pública.

De fato, entendemos política como uma ação contínua, que visa atender a problemas, necessidades e anseios de uma sociedade marcada por contextos, história, fatores e múltiplas formas relacionamentos, sendo assim, tudo ocorre por meio de condições e possibilidades estabelecidos dentro daquele contexto social.

Por fim, nos cabe analisar as políticas públicas em Educação do Campo, a partir de um viés que as diferenças dos grupos sociais, seus anseios, os diferentes contextos, sujeitos e sentidos das práticas sociais sejam legitimadas e consideradas, pois as políticas como conjunto de ações são constituídas por discursos. Portanto, é de extrema importância que tanto na sua formulação/ implementação, quanto na sua análise esses aspectos sejam considerados de modo a legitimar as identidades e os valores dos diferentes grupos sociais.

\section{REFERÊNCIAS BIBLIOGRÁFICAS}

AZEVEDO, J. M. L. A educação como política pública. 3.ed.Campinas, SP: Autores Associados, 2004.

BALL, S. J.; MAINARDES, J. (Orgs.). Políticas educacionais: questões e dilemas. São Paulo: Cortez, 2011.

BURITY, J. A. Discurso, política e sujeito na teoria da hegemonia de Ernesto Laclau; Ernesto Laclau. "Posfácio". In: MENDONÇA, D; PEIXOTO RODRIGUES, L. Pós-estruturalismo e teoria do discurso: em torno de Ernesto Laclau. Porto Alegre: EDIPUCRS, 2008.

CUNHA, K. A teoria do discurso como abordagem teórica e metodológica no campo das políticas públicas em educação. Revista Estudos Políticos, nº 7, jul/ dez 2013, p. 257- 276.

LACLAU, E. ; MOUFFE, C. Hegemonia e estratégia socialista: por uma política democrática radical. Tradução de Joanildo A. Burity, Josias de Paula Jr. E Aécio Amaral. São Paulo: Intermeios. Brasília: CNPq, 2015. (Coleção Contrassensos)

LACLAU, E. Posmarxismo sin pedidos de desculpas com Chantal Mouffe, 1987. Cap.2. LACLAU, Ernesto. Nuevas reflexiones sobre la revolución em nuestro tempo. Buenos Aires: Nueva Visión, 1993, p. 111- 145.

LOPES, A. C. Teoria pós-críticas, política e currículo. Revista Educação, sociedade e culturas, $n^{\circ} 39,2013$, p. 7- 23.

MINAYO, M. C. S. (org.). Pesquisa Social: Teoria, método e criatividade. 32 Ed. Petrópolis: Vozes, 2012.

PETERS, M. Pós-estruturalismo e filosofia da diferença. Belo Horizonte: Autêntica, 2000. 
RODRIGUES, L. P; MENDONÇA, D. Pós-estruturalismo e teoria do discurso: em torno de Ernesto Laclau. Porto Alegre: EDIPUCRS, 2008.

SOUZA, C. Políticas públicas: uma revisão da literatura. Sociologias, Porto Alegre. Ano 8, no 16, jul/dez 2006, p. 20-45. 